\title{
The Relation between Five-Factor Personality Traits and Risk-Taking Behavior in Preadolescents
}

\author{
Ronnie L. McGhee ${ }^{1}$, David J. Ehrler ${ }^{1}$, Joseph A. Buckhalt ${ }^{2}$, Carol Phillips ${ }^{3}$ \\ ${ }^{1}$ Clocktower Hill Research and Publishing Group, Rome, USA \\ ${ }^{2}$ Auburn University, Auburn, USA \\ ${ }^{3}$ Lee County School System, Leesburg, USA \\ Email: research@clocktowerhill.com
}

Received February 18 , $^{\text {th }}$ 2012; revised April 5 ${ }^{\text {th }}$, 2012; accepted June $7^{\text {th }}, 2012$

\begin{abstract}
The predictive relation between Five-Factor Model (FFM) personality traits using the Five Factor Personality Inventory-Children (FFPI-C) and degrees of risk-taking in preadolescents (ages 10 to 12) was studied in a sample of 50 fifth-graders. Results indicated that high Extraversion and Openness to Experience and low Conscientiousness were correlated with high risk-taking. The FFPI-C factors were significantly predictive of risk-taking behavior, and accounted for $42 \%$ of the risk-taking variance, based on a multiple regression analysis. These findings suggest that the same mechanisms that are associated with adult risk-taking may already be present in children as young as 10 to 12 years of age.
\end{abstract}

Keywords: Risk-Taking; Five Factor Model; Preadolescents; Personality; Child Development

\section{Introduction}

High and low risk-taking behavior in preadolescence can take many forms (e.g. avoiding learning to swim, climbing to the highest tree limb, coin flipping to decide possession of the last cookie, accepting a dare to damage property, unwillingness to guess on a test question, using illegal drugs, participating in a drama club, shop lifting, and having unprotected sex with a stranger). Some of these behaviors have benign consequences while others may be life threatening. Although several definitions of risk-taking exist, the authors consider the one proffered by The Centre for Cancer Education, University of Newcastle (2007) to be exceptionally well operationalized: "Undertaking a task involving a challenge for achievement or desirable goal in which there is a lack of certainty or a fear of failure. It may also include the exhibiting of certain behaviors whose outcomes may present a risk to the individual and/or to those associated with him or her."

Risk-taking in adolescence has been a focus of research for a long time, but few theoretical frameworks have been advanced to guide satisfactory explanations and successful interventions (Steinberg, 2004, 2007). Additionally, the nature of risk-taking in preadolescence is not well conceived at this time, as 1) there are few scientific studies examining this personal trait at this age; and 2) there is no comprehensive predictive model of risk-taking in preadolescence (Furby \& Beyth-Marom, 1992).

Intra-individual predispositions, often referred to as personality traits, are proposed to be important in the prediction of high and low risk-taking behavior. In this model, degrees of risk-taking are a function of self-regulatory aspects of personality (Hoyle, 2006). An example of this relation is reported by Huth-Bocks (2008) who found that sensation-seeking behavior (substance abuse and unsafe sex) in university students was associated with high extraversion in females and low agreeableness and low conscientiousness in the entire sample (males and females).
The Five-Factor Model (FFM) of personality has become a "standard vocabulary or nomenclature" (John, 1990) used by researchers to describe intra-individual predispositions (i.e., temperament). According to this model, the dimensions of the FFM represent the fundamental ways in which persons differ (McCrae \& John, 1992) and both explain present behavior and predict future actions (in this case, risk-taking behavior). Table 1 presents descriptions of the FFM personality dimensions.

The relation between FFM personality traits and risk-taking in adolescents and adults is well established in the research literature. Mecca (2003) reported strong relations between pathological gambling and the FFM traits of neuroticism, agreeableness, and conscientiousness while Hoyle, Feifar and Miller (2000) found a relation between sexual risk-taking in adults and the traits of neuroticism and conscientiousness. Gullone and Moore (2000) investigated the relation between adolescent risk-taking judgments and the five-factor model of personality. They reported that high risk-taking girls scored higher on scales of neuroticism, agreeableness and conscientiousness than boys. Taken together, risk judgments, personality factors, age and sex were found to be significant predictors of risk behaviors in adolescents. Finally, Zuckerman and Kuhlman (2000) studied a college student sample and found that generalized risk-taking was related to scales for impulsive sensation seeking, aggression, and sociability, but not to scales for neuroticism or activity.

Given our review of the literature, it is evident that aspects of the FFM are correlated with, and predictive of, risk-taking behavior in adolescents and adults. As researchers have found the FFM to be stable from childhood adulthood (Aklin et al., 2004; Asendorpf \& Van Aken, 2003), it is therefore hypothesized that FFM personality traits in preadolescents, too, are correlated with, and predictive of, risk-taking behavior. In the present study, we seek to identify the predictive relation between the FFM personality traits to risk-taking in preadolescents, an understudied population. The research questions in this study are 
Table 1.

Description of the Five-Factor Model of personality dimensions.

\begin{tabular}{lcl}
\hline Personality Dimension & Code & \\
\hline Agreeableness & A & One’s propensity to be trusting, altruistic, compliant, modest, genuine, and sympathetic toward others. \\
$\begin{array}{lcl}\text { Extraversion } & \text { E } & \text { One’s propensity to be gregarious, assertive, friendly, excitement-seeking, fast-paced, and high-spirited. } \\
\text { Openness to Experience } & \text { O } & \begin{array}{l}\text { One’s propensity to be intellectually curious, appreciative of novelty, interested in art, music, and beauty, } \\
\text { and imaginative and creative. }\end{array} \\
\text { Conscientiousness } & \mathrm{C} & \text { One’s propensity to be dutiful, orderly, self-disciplined, deliberate, and achievement striving. } \\
\text { Emotional Regulation (Neuroticism) }\end{array}$ & $\mathrm{R}$ & One’s propensity to be resistant to stress, anxiety, depression, anger/hostility, and self-consciousness. \\
\hline
\end{tabular}

Note: "The FFM instrument employed in this study utilizes the term “Emotional Regulation” and is considered synonymous with Neuroticism.

as follows: 1) Are FFM personality traits related to risk-taking behavior in preadolescents using an experimental measure of risk of failure, and 2) Can risk-taking behavior be profiled through a predictive model using the FFM of personality?

\section{Method}

\section{Participants}

Participants in the study were drawn from a public school system in Georgia, USA. Two heterogeneously grouped $5^{\text {th }}$ grade homeroom classrooms were randomly selected from nine $5^{\text {th }}$ grade classrooms. Of the 50 potential participants, all provided parental consent and personal assent to participate, and all 50 potential participants completed the study. Twenty-seven participants were male and 23 were female. Forty of the participants self-identified as White or Caucasian, 7 identified as Black or African-American, two identified as Hispanic, and one identified as Asian. The average age of the participants was 11 years; the youngest participant was 10 and the oldest participant was 12 .

\section{Instruments and Procedures}

Personality Assessment. The personality assessment component of the study was conducted first. The Five Factor Personality Inventory-Children (FFPI-C; McGhee, Ehrler, \& Buckhalt, 2007) was group administered in one session to each class following standardized instructions stated in the manual and then were scored by two experienced school psychologists. The FFPI-C is a standardized measure of the FFM for children and adolescents between the ages of 9 - 0 and 18 - 11. The FFPI-C consists of 75 items and can be completed as either an individually or group administered self-report inventory. The scale labels are consistent with FFM descriptive lexicon, including Agreeableness, Extraversion, Openness to Experience, Conscientiousness, and Emotional Regulation. High T-scores represent high levels of the respective FFM personality trait, whereas low T-scores represent low levels of the respective FFM personality trait. Suldo and Steward (2008), in a review of the FFPI-C, found the instrument to have adequate psychometric characteristics for research purposes and support for construct validity.

Risk-Taking Task. To evaluate risk-taking behavior in this study in a manner conforming to the previously cited definition (Centre for Cancer Education, University of Newcastle, 2007), we created a novel decision-making task that included the elements of fear of failure and uncertainty. In this task, children's propensity to make a choice that involves high-risk of failure or opt for a known safe choice was evaluated and recorded. Participants were presented with three opportunities to make choices that varied in degree of potential for success and failure. One choice was guaranteed a success, but the reward had minimal value. The other choices had high potential for failure (75 percent chance), but success yielded a reward with considerably greater value (10 times the value of the safe choice).

Individual participants entered an office containing a table, desk and two chairs. They were instructed to sit down facing the examiner at the desk. The examiner then gave the following oral directions:

"You are going to play a decision-making game. You will have three chances [rounds of the game] to make a choice with the possibility of earning treats. So, before we plan this game, which of these treat would you like the chance to find and keep [examiner gestures to one type of fruit and two types of candy and waits for the participant to choose]? Great, now look at these cups [examiner gestures to five plastic cups]. There is one blue cup and 4 red cups. I will put one treat under the blue cup and place it in the middle [examiner gestures to middle of table]. Remember, there will always be one treat under the blue cup. I will then place ten treats under one of the red cups, but you will not know which of the four red cups they will be under. When I say ready, chose only one cup by pointing. If there are treats under your chosen cup, they are yours to keep. Remember, you will have three chances to play this game. Do you understand?”

On completion of the oral directions and choosing their preferred treats, participants were shown five plastic cups; one blue cup and 4 red cups. In view of the participant, one piece of the chosen treat was placed under the blue cup and positioned in the middle of the table. The examiner then placed 10 chosen treats in 1 red cup. The remaining 3 red cups were shown to the participant as having nothing under them. A cardboard partition was placed between the participant and the examiner and the 4 red cups were placed in line with the blue cup; two to the right and 2 to the left of the blue cup. The position of the "10-treat red cup" was predetermined for each round of the game (position 2 for round 1, position 4 for round 2, and position 4 for round 3 ). The barrier was then removed and the participant was instructed to choose one cup by pointing. Once choice was made, the location of the choice was recorded and the cup overturned. If a treat(s) was under the chosen cup, they were placed in a bag labeled with the child's name for later dispersal. All cups were then overturned. This procedure was repeated for the last two rounds. Participants who completed the study were sequestered so that no information about the exercise could be shared among succeeding participants. Figure 1 illustrates the physical layout used in the task. 


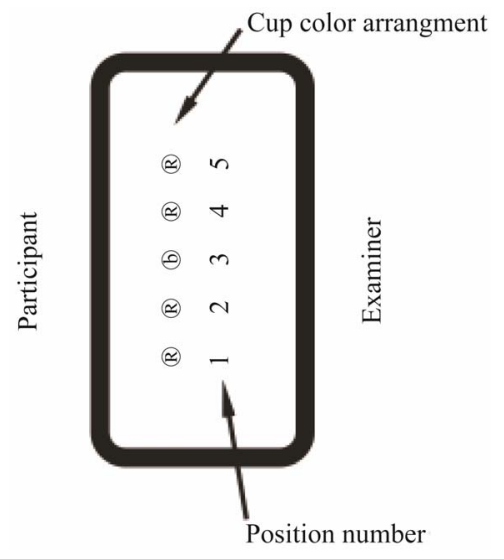

Figure 1.

Risk-taking task arrangement.

\section{Results}

Means and standard deviations for scores on risk-taking and FFPI-C scales are presented in Table 2. Correlations between risk-taking scores and FFM personality dimensions and FFPI-C inter-scale correlations are reported in Table 3. The statistical significance of correlations is distinguished at both the .05 and .01 alpha levels. Using Hopkins' (2002) Likert-scale approach to evaluating the magnitude of absolute correlations, correlations between .0 and .1 are considered very small to trivial, coefficients between .1 and .3 are small, coefficients between .3 and .5 are moderate, coefficients between .5 and .7 are large, and coefficients between .7 and 1.00 are very large.

Table 2.

Descriptive statistics.

\begin{tabular}{lcc}
\hline Variable & Mean & Standard Deviation \\
\hline Risk-Taking Choices & .84 & .93 \\
Agreeableness (A) & 51.74 & 9.76 \\
Extraversion (E) & 50.56 & 9.87 \\
Openness to Experience (O) & 49.86 & 9.73 \\
Conscientiousness (C) & 51.86 & 8.72 \\
Emotional Regulation (R) & 53.64 & 9.05 \\
\hline
\end{tabular}

Note: reported FFPIC scores are T scores.

Table 3.

Correlations among Risk-Taking Choices and Personality Factors.

\begin{tabular}{lcccccc}
\hline & $\begin{array}{c}\text { Risk-Taking } \\
\text { Choices }\end{array}$ & $\mathrm{A}$ & $\mathrm{E}$ & $\mathrm{O}$ & $\mathrm{C}$ & $\mathrm{R}$ \\
\hline Risk-Taking Choices & -- & & & & & \\
Agreeableness (A) & -.253 & -- & & & & \\
Extraversion (E) & $-.539^{* *}$ & $.334^{*}$ & -- & & & \\
Openness to Experience (O) & $.330^{*}$ & $-.397^{* *}$ & -.129 & -- & & \\
Conscientiousness (C) & $-.316^{*}$ & $-.588^{* *}$ & $.486^{* *}-.231$ & -- & \\
Emotional Regulation (R) & -.213 & $-.288^{*}$ & .263 & .140 & $-.438^{* *}$ & -- \\
\hline
\end{tabular}

Note: ${ }^{* *}$ Correlations are significant at the .01 alpha level. ${ }^{*}$ Correlations are significant at the .05 alpha level.
As presented in Table 3, of the FFPI-C scales, Extraversion significantly correlated to a large degree with risk-taking and Openness to Experience correlated moderately with risk-taking. Conscientiousness correlated moderately and negatively with risk-taking. That is, participants who self-reported having a highly conscientious disposition were less likely to engage in risk-taking. Small and non-significant correlations were found between risk-taking and FFPI-C scales of Agreeableness and Emotional Regulation.

To determine the predictive contribution of the FFM to risk-taking behavior, a multiple regression analysis was conducted. Risk-taking was regressed onto the FFM dimensions as measured by the FFPI-C scales. The FFM was found to be significant in the prediction of risk-taking behavior, $\mathrm{F}(5,44)=6.364, p$ $<.001$. The overall model accounted for $42 \%$ of the variance in risk-taking choices $\left(\mathrm{R}^{2}=.42\right)$. Of the FFM dimensions, Extraversion and Openness to Experience added significantly to the prediction of risk-taking behavior. Openness to Experience (Beta $=.419, p=.004$ ) accounted for the greatest variance when predicting risk-taking behavior, while Extraversion (Beta $=.36,1 p=.013$ ) accounted for slightly less variance. Agreeableness (Beta $=-.246, p=.119$ ), Conscientiousness (Beta $=-.120, p=.470$ ), and Emotional Regulation (Beta $=.065, p=.633$ ) were non-significant in the prediction model.

\section{Discussion}

Large relations were identified between high risk-taking and certain FFM traits. Specifically, preadolescents when engaged in the highest risk-taking were found to be extroverted (high extraversion), open to new experiences (high openness to experience) and lacking in conscientiousness (low conscientiousness). It is not surprising that Extraversion was found to be positively correlated with high levels of risk-taking behavior. McCrae \& Costa (1990) report several subfacets of the Extraversion factor that appear to incorporate the propensity for sensation seeking and risk-taking behaviors. Furthermore, since the broad definition of Openness is a willingness to make oneself available to new experiences, it is hypothesized that children with this profile were intrigued by participating in a novel dilemma game and may have viewed the riskier choice as more interesting. Regarding the finding that children with high levels of conscientiousness were less likely to take risks in the exercise, it is our hypothesis that they are unwilling to venture failure, even in low stakes situations. One subfacet of Conscientiousness is the strong desire to be correct; sometimes to the point of perfectionism. Given this predisposition, we would expect children low in Contentiousness to be unencumbered by fear of failure. Although no significant relation was found between risk-taking and the personality traits of neuroticism and agreeableness, these findings are not surprising given that the experimental risk-taking task did not involve participation in behaviors with elicitation of strong emotion or stress, nor did it involve social coercion, manipulation, or collaboration (i.e. there was no mechanism present that might be construed as requiring a strong "pull” from the agreeableness trait). Overall, we can conclude that factors that are associated with adult risk-taking behavior (e.g. Huth-Bock, 1996) also appear present in children as young as 10 to 12 years of age.

Our findings support the conclusion that risk-taking behavior can be identified through a predictive model using intra-individual predispositions, as specified using the FFM of personality. 
When all five FFPI-C scales were included in a multiple regression analysis with level of risk-taking set as the dependent variable, the dimensions of Extraversion and Openness to Experience added significantly to the prediction of risk-taking behavior. Openness to Experience accounted for the greatest variance while Extraversion accounted for slightly less variance. Agreeableness, Conscientiousness, and Emotional Regulation were non-significant in the prediction model.

There remain many unanswered questions about the relation between personality and risk-taking in preadolescents. First, the risk-taking task in this study focused on "fear-of-failure" and not "fear-of-loss". Had it examined the latter, findings may have been different. Secondly, the current study examined risk-taking in a very narrow age-range and did not involve a longitudinal perspective. Thirdly, we concur with other researchers (Lavery, 1993; Steinberg, 2007) who argue that risk-taking is a multidimensional phenomenon involving personality correlates, selfregulating processes, and most likely cognitive aspects of decision-making including executive functions. Use of personality traits alone to model risk-taking behavior in children may be too constrained.

\section{REFERENCES}

Abe, J. A. (2005). The predictive validity of the Five-Factor Model of personality with preschool age children: A nine year follow-up study. Journal of Research in Personality, 39, 423-442. doi:10.1016/j.jrp.2004.05.002

Aklin, W. M., Lejuez, C. W., Zvolensky, M. J., Kahler, C. W., \& Gwadz, M. (2004). Evaluation of behavioral measures of risk taking propensity with inner city adolescents. Behavior Research and Therapy, 43, 215-228. doi:10.1016/j.brat.2003.12.007

Asendorpf, J. B., \& Van Aken, M. A. G. (2003). Validity of the big five personality judgments in childhood: A 9 year longitudinal study. European Journal of Personality, 17, 1-17. doi:10.1002/per.460

Bechara, A., Damaisio, A. R., Damaisio, H., \& Anderson, S. W. (1994). Insensitivity to future consequences following damage to the human prefrontal cortex. Cognition, 50, 7-15.

doi:10.1016/0010-0277(94)90018-3

Centre for Cancer Education, University of Newcastle (2008). A definition of risk-taking. URL (last checked 26 September 2008). http://cancerweb.ncl.ac.uk/cgi-bin/omd?risk-taking.

Ehrler, D. J., Evans, J. G., \& McGhee, R. L. (1999). Extending big-five theory into childhood: A preliminary investigation into the relationship between big-five personality traits and behavior problems in children. Psychology in the Schools, 36, 451-458.

doi:10.1002/(SICI)1520-6807(199911)36:6<451::AID-PITS1>3.0.C O;2-E

Furby, L., \& Beyth-Marom, R. (1992). Risk-taking in adolescence: A decision-making perspective. Developmental Review, 12, 1-44. doi:10.1016/0273-2297(92)90002-J

Gramzow, R. H., Sedikides, C., Panter, A. T., Sathy, V., Harris, J., \& Insko, C. A. (2004). Patterns of self-regulation and the big five. European Journal of Personality, 18, 367-385. doi:10.1002/per.513

Gullone, E., \& Moore, S. (2000). Adolescent risk-taking and the five-factor model of personality. Journal of Adolescence, 23, 393407. doi:10.1006/jado.2000.0327

Hopkins, W. G. (2002). A scale of magnitudes for effect statistics. A new view of statistics. URL (last checked 13 June 2002). www.sportsci.org/resource/stats/effectmag.html.

Hoyle, R. H. (2006). Personality and self-regulation: Trait and information-processing perspectives. Journal of Personality, 74, 1507 1525. doi:10.1111/j.1467-6494.2006.00418.x

Hoyle, R. H., Feifar, M. C., \& Miller, J. D. (2000). Personality and sexual risk taking: A quantitative review. Journal of Personality, 68, 1203-1231. doi:10.1111/1467-6494.00132

Huth-Bocks, A. C. (1996). Personality, sensation seeking, and risktaking behavior in a college population. Psy Chi Online Journal, 1. http://www.psichi.org/pubs/issue.asp?issue_id=62.

John, O. P. (1990). The "Big Five" factor taxonomy: Dimensions of personality in the natural language and in questionnaires. In L. A. Pervin (Ed.), Handbook of personality: Theory and research (pp. 66-100). New York: Guilford.

Lavery, B., Siegel, A. W., Cousins, J. H., \& Rubovits, D. S. (1993). Adolescent risk-taking: An analysis of problem behaviors in problem children. Journal of Experimental Child Psychology, 55, 277-294. doi:10.1006/jecp.1993.1016

Lejuez, C. W., Read, J. P., Kahler, C. W., Richards, J. B., Ramsey, S. E., Stuart, G. L. et al. (2002). Evaluation of a behavioral measure of risk-taking: The Balloon Analogue Risk Task (BART). Journal of Experimental Psychology: Applied, 8, 75-84. doi:10.1037/1076-898X.8.2.75

McCrae, R. R., \& John, O. P. (1992). An introduction to the five-factor model and its applications. Journal of Personality, 60, 175-215. doi:10.1111/j.1467-6494.1992.tb00970.x

McCrae, R. R., \& Costa, P. T. (1990). Personality in adulthood. New York: The Guilford Press.

McGhee, R. L., Ehrler, D. J., \& Buckhalt, J. A. (2007). Five Factor Personality Inventory-Children. Austin, TX: PRO-ED.

Mecca, D. N. (2003). The relationship between pathological gambling and the Big-Five personality factors. Unpublished master's thesis, New Britain, CT: Central Connecticut State University.

Miller, D. C., \& James, P. B. ((1997). The role of contextual and personal factors in children's risk taking. Developmental Psychology, 33, 814-823. doi:10.1037/0012-1649.33.5.814

Morrongiello, B. A., \& Matheis, S. (2007). Understanding children’s injury-risk behaviors: The independent contributions of cognitions and emotions. Journal of Pediatric Psychology, 32, 926-937. doi:10.1093/jpepsy/jsm027

Morrongiello, B. A. \& Rennie, H. (1998). Why do boys engage in more risk taking than girls? The role of attributions, beliefs, and risk appraisals. Journal of Pediatric Psychology, 23, 33-43. doi:10.1093/jpepsy/23.1.33

Potts, R., Martinez, I. G., \& Dedom, A. (1995). Childhood risk taking and injury: Self-report and informant measures. Journal of Pediatric Psychology, 20, 5-12. doi:10.1093/jpepsy/20.1.5

Steinberg, L. (2004). Risk-taking in adolescence: What changes, and why? Annals of the New York Academy of Sciences, 1021, 51-58. doi:10.1196/annals.1308.005

Steinberg, L. (2007). Risk taking in adolescence. Current Directions in Psychological Science, 16, 55-59. doi:10.1111/j.1467-8721.2007.00475.x

Suldo, M. S., \& Stewart, T. N. (2008). Test review: Five Factor Personality Inventory-Children. Journal of Psychoeducational Assessment, 26, 202-209. doi:10.1177/0734282907312830

Zuckerman, M., \& Kuhlman, D. M. (2000). Personality and risk-taking: Common biosocial factors. Journal of Personality, 68, 999-1029. doi:10.1111/1467-6494.00124 